\title{
Characteristic Analysis of Seal Type Hydraulic Dumper Based on AMESim
}

\author{
Jungong $\mathrm{Ma}^{1, \mathrm{a}}$, Weiping Wang ${ }^{1, \mathrm{~b}}$, Qiang $\mathrm{Wu}^{2, \mathrm{c}}$ \\ ${ }^{1}$ Beihang University, Beijing 100191, China \\ ${ }^{2}$ Mailbox NO.43, Yangxian, Shaanxi 723313, China \\ a1196474894@qq.com, bsnowney44@126.com, cwuqaing@126.com
}

Keywords: seal type Hydraulic dumper, AMESim, dynamic characteristic, power diagram.

Abstract. Seal type hydraulic dumper is frequently used in helicopter rotor system to prevent ground resonance and air resonance. In this paper, we modeled the seal type hydraulic dumper with the Hydraulic Component Design database in AMESim and analyzed the impact of driving frequency and gas content of the hydraulic oil. The area surrounded by the power diagram extends with the increase of the driving frequency and shrinks with the increase of the gas content in hydraulic oil. These conclusions may do benefit to the design and selection of hydraulic damper.

\section{Introduction}

With the development of the aviation industry, helicopters are more and more important for the enormous maneuverability [1]. In military field, they can be used in air-landing, battlefield rescuing, reconnaissance patrols and so on [2]. In civilian field, they can be used in Medicare, equipment lifting, aerial photography. Lift provided by one or more horizontal rotating rotors is the significant feature of helicopter.

Rotors are rotating in a high speed while helicopters are in working process [3]. In this case, resonance phenomenon does occur between the rotating shaft and the body of the helicopter. And this will lead to serious consequences, even damage of the helicopter and people. Therefore, seal type hydraulic damper are usually used as connection between the rotating shaft and the body of the helicopter [4]. Thus damping capacity of hydraulic damper is worth to be studied.

\section{Working principle of hydraulic damper}

Hydraulic damper can decrease vibration of the rotating shaft. However, considering the strength of the rotating shaft, it's essential to set safety valve in hydraulic damper. There are two working states of hydraulic damper. When speed of the extension rod is low, the damping capacity of hydraulic damper depends on the velocity loss of the hydraulic oil through the inner thin-wall orifice. When speed of the extension rod is high, it depends on the inner constant pressure damping valve. And we also need to take the negative pressure into consideration when the speed is too high. So ususlly, filling-oil device is necessary for hydraulic damper. The working principle of hydraulic damper is shown in fig.1.

\section{Construction of AMESim model for hydraulic damper}

For most devices, there is no corresponding models in AMESim. So they need to be constructed by the hydraulic components design database in AMESim. We constructed the hydraulic damper model in this way considering the leakage of all the orifices, mass of all the valve spool, gas content of the hydraulic oil, and the details are shown in fig.2. 


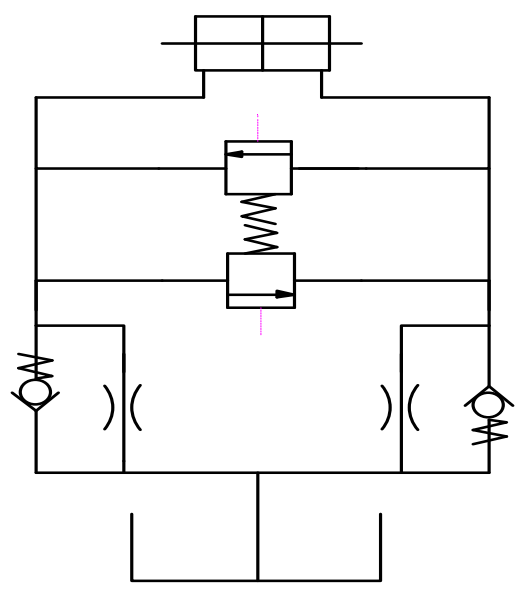

Fig1. Working principle of hydraulic damper

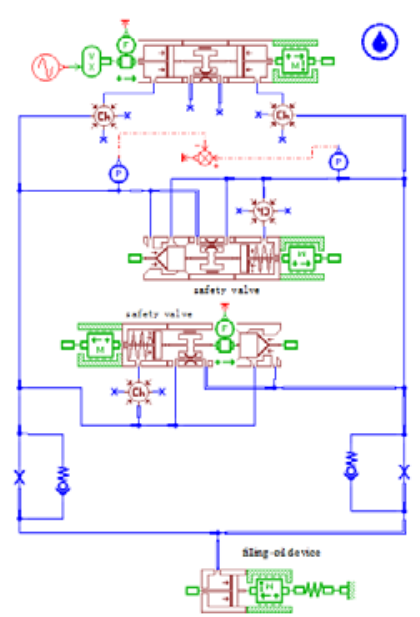

Fig2. Model of hydraulic damper

\section{Simulation and analysis of the results}

Considering the volume of hydraulic damper, the pipeline is simplified in our simulation. All the parameters of pipeline are set as $6 \mathrm{~mm}$ for diameter and $50 \mathrm{~mm}$ for length.

Since hydraulic damper is power consuming device in essence, power diagrams are applied to measure its power consuming ability, in which $\mathrm{x}$ axis is set as displacement of extension rod of hydraulic damper while y axis is set as the outputting power of hydraulic damper. In this diagram, the ability of power consuming of hydraulic damper can be reflected by the encircled area of the curve.

Other simulation parameters are shown in table 1.

Table.1 parameters value table

\begin{tabular}{|c|c|}
\hline parameters & value \\
\hline Piston diamater & $20 \mathrm{~mm}$ \\
\hline Piston rod diamater & $5 \mathrm{~mm}$ \\
\hline Length of the cylinder & $\pm 20 \mathrm{~mm}$ \\
\hline equivalent orifice diameter & $2.9 \mathrm{~mm}$ \\
\hline relief valve cracking pressure & $10 \mathrm{MPa}$ \\
\hline
\end{tabular}

\subsection{Effect of driving frequency on capability of hydraulic damper}

Input signal is set as the displacement of hydraulic damper extension rod, which is

$$
x=0.1 \sin (A \pi t) \text {. }
$$

Set different values of $A$ to change the frequency of input driving signal as $1,2,4,8$, while the frequency is $0.5 \mathrm{~Hz}, 1 \mathrm{~Hz}, 2 \mathrm{~Hz}, 4 \mathrm{~Hz}$ respectively. Gas content is set as $5 \%$ and simulation time is 4s. Simulation result of output force is shown in fig.3.

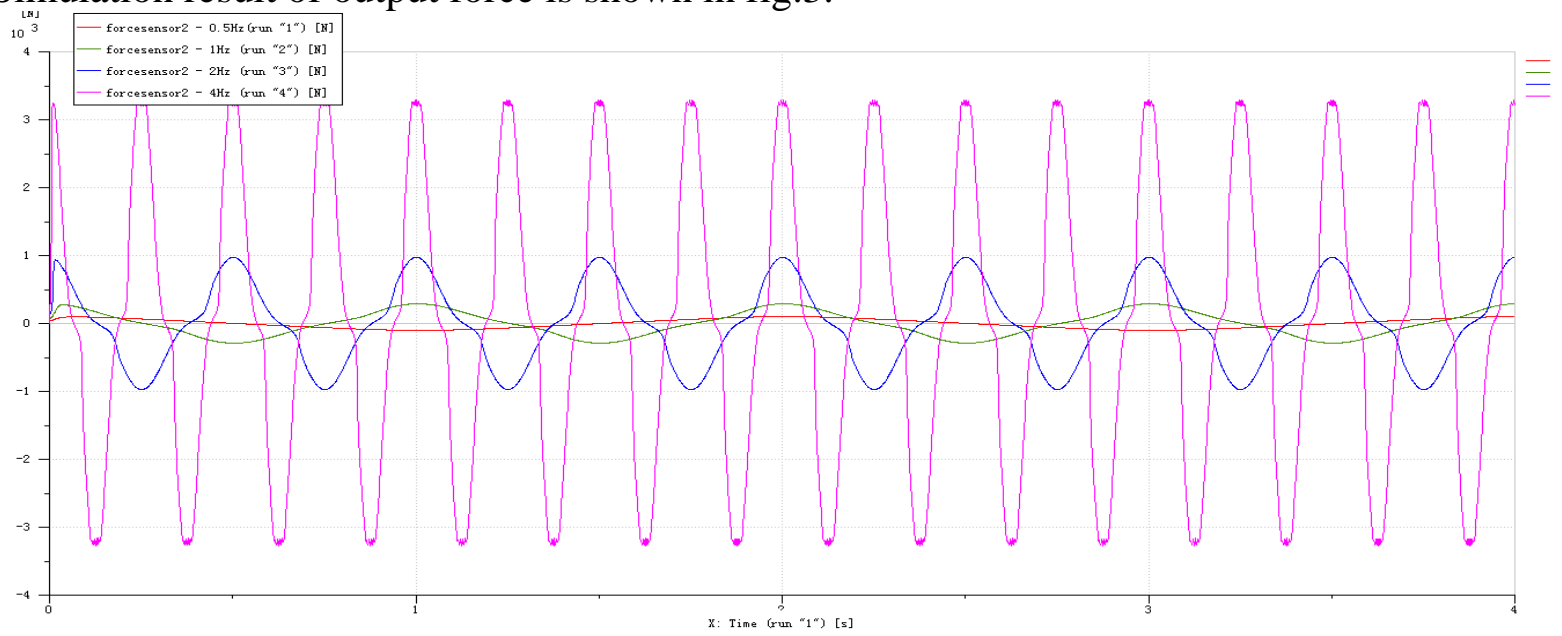

Fig.3 response output force of different driving frequency

The power diagram based on fig. 3 is shown in fig. 4 . 


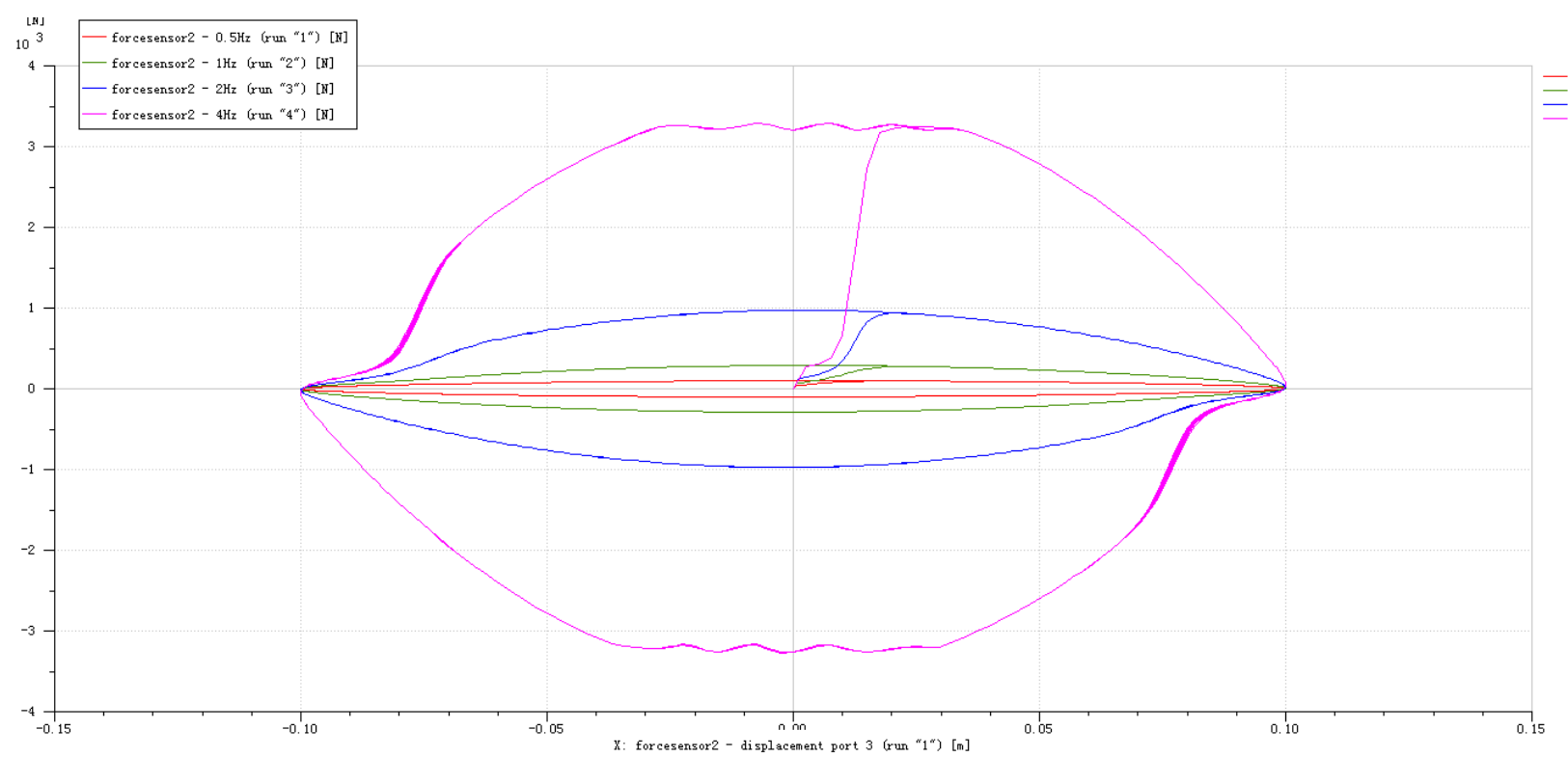

Fig.4 response power diagram of different driving frequency

Fig3 and fig4 show that the hydraulic damper need a proper driving frequency to ensure the power consuming capability. This is because hydraulic damper is sensitive about the velocity of the extension rod. When the extension rod moves to the right, just as shown in fig5, we can calculate the outputting force in this way.

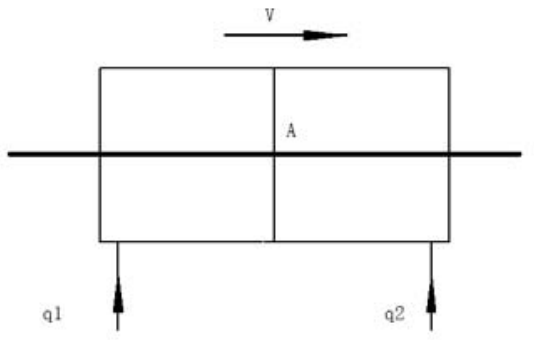

Fig.5 working condition diagram of the hydraulic damper

The pressure of the right chamber is much higher than the left by this time because of the dumping orifice. We need to calculate the pressure difference.

$$
\begin{gathered}
Q_{2}=-Q_{c l}+a_{2} v \\
Q_{c l}=\frac{\pi d \delta^{3}}{12 u l} \Delta p\left(1+1.5 \varepsilon^{2}\right)-\frac{\pi d \delta}{2} v \\
Q=C_{q} A \sqrt{\frac{2 \Delta p}{\rho}} \\
\Delta p=P_{2}-P_{1}
\end{gathered}
$$

These equations show the relationship between the pressure difference and the velocity of the extension rod. The square of the velocity is linear to the pressure difference. And the driving frequency represent the velocity. So users must ensure their chosen hydraulic damper can work at the proper condition after the external parameters are confirmed.

\subsection{The effect of gas content in hydraulic oil on capability of hydraulic damper}

Set the driving frequency as $4 \mathrm{~Hz}$ and simulation time as $0.5 \mathrm{~s}$. In order to study the effect of gas content in hydraulic oil on capability of hydraulic damper, gas content are set as $0.1 \%, 1 \%, 5 \%, 10 \%$ respectively. Simulation result of output force is shown in fig.6. 


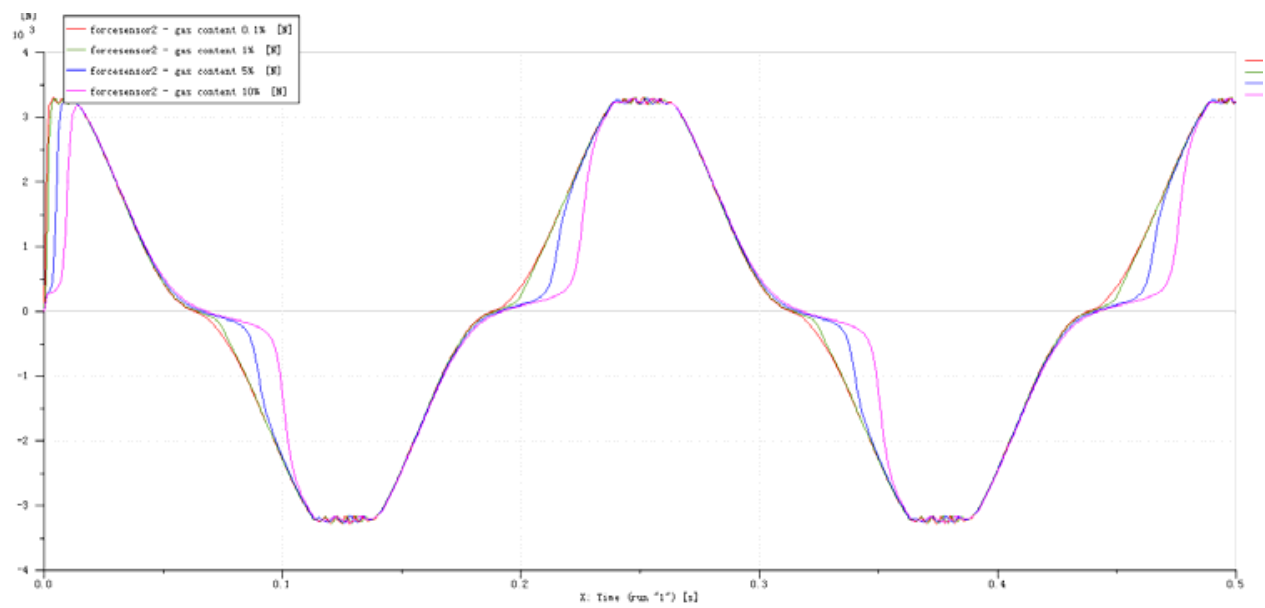

Fig.6 response output force of different gas content in hydraulic oil

Fig6 shows that the output force curve skewed to the right with the increase of the gas content in hydraulic oil. The power diagram based on fig.6 is shown in fig.7.

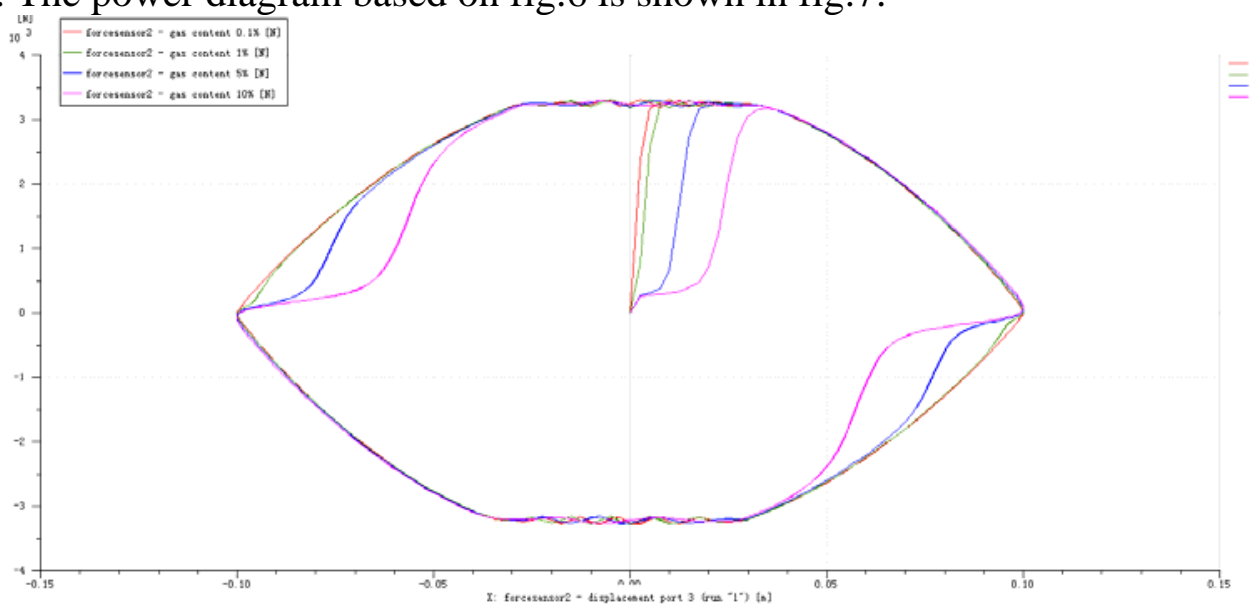

Fig.7 response power diagram of different gas content in hydraulic oil

From fig7, we can see that the power consuming capability of hydraulic damper decreases with the increase of the gas content in hydraulic oil. For general hydraulic system, gas content in hydraulic oil is $1 \%-5 \%$. However, for the hydraulic damper, the power consuming capability of hydraulic damper decreased by $20 \%$ when the gas content changed from $1 \%$ to $5 \%$. Therefore, to guarantee the power consuming capability of hydraulic damper, gas filtration is necessary during production and using process.

\section{Conclusion}

In this paper, seal type of hydraulic damper is modeled and simulated with AMESim. And the results indicate the tendency of the output power diagram with the variation of the driving frequency and the gas content of the hydraulic oil. This conclusion can support the design of hydraulic damper and can help model selection for users.

\section{References}

[1] LI M F. Hydraulic damper design calculate of one type helicopter. Helicopter Technique, 2009, 03: 72 75(in Chinese)

[2] GU H B, Ding Y L. Effects of fluid compressibility on landing gear shimmy dampers. Journal of Nanjing University of Aeronautics\& Astronautics, 1999, 12(6): 626 633(in Chinese)

[3] XIE L Y, The research and applications of hydraulic lead-lag damper of helicopter. Helicopter Technique, 2004, 02: 24 27(in Chinese)

[4] Bousman W G, Wiukler D J. Application of the moving-block analysis [A]. The $22^{\text {nd }}$ Structure, Structural Dynamics and Materials Conference and Adaptive Structures Forum [C], 1981 